\title{
$\widehat{A}$ Madridge
}

madridge Journal of Internal and Emergency Medicine

\author{
Interconnecting Scientific World
}

Research Article

Open Access

\section{Utility of an Ambulance Offload Nurse on Emergency Department Metrics}

\author{
Qamar Amin ${ }^{1,2 \star}$, Waleed Alqurashi ${ }^{3}$, Jeffrey Perry ${ }^{3}$, Frank Battaglia ${ }^{4}$, Kaushik Chattopadhyay ${ }^{2,5}$, \\ Abdulaziz Alsadoon ${ }^{3}$, Sasha Uppal ${ }^{6}$, Leila Salehi ${ }^{1}$, Shawn Mondoux ${ }^{7}$, Prashant Phalpher ${ }^{1}$ and Rahim Valani ${ }^{7}$ \\ ${ }^{\prime}$ Department of Family Medicine, McMaster University, Hamilton, Canada \\ ${ }^{2}$ Faculty of Public Health and Policy, London School of Hygiene and Tropical Medicine, London, UK \\ ${ }^{3}$ Department of Emergency Medicine, Clinical Epidemiology Program, Ottawa Hospital Research Institute, University of Ottawa, Ottawa, Canada \\ ${ }^{4}$ Faculty of Medicine, University of Ottawa, Canada \\ ${ }^{5}$ Division of Epidemiology and Public Health, University of Nottingham, Nottingham, UK \\ ${ }^{6}$ University of Windsor School of Medicine, Saint Kitts, West Indies \\ ${ }^{7}$ Department of Medicine, McMaster University, Hamilton, Canada
}

\section{Article Info}

*Corresponding author:
Qamar Amin
Professor
Department of Emergency Medicine
McMaster University
2100 Bovaird Drive East Brampton
Ontario L6R 3J7
Canada
Tel: $905-494-2120$
E-mail: qamaramin@gmail.com

Received: June 18, 2019

Accepted: June 24, 2019

Published: July 2, 2019

Citation: Amin Q, Alqurashi W, Perry J, et al. Utility of an Ambulance Offload Nurse on Emergency Department Metrics. Madridge J Intern Emerg Med. 2019; 3(2): 128-132. doi: 10.18689/mjiem-1000130

Copyright: (c) 2019 The Author(s). This work is licensed under a Creative Commons Attribution 4.0 International License, which permits unrestricted use, distribution, and reproduction in any medium, provided the original work is properly cited.

Published by Madridge Publishers

\begin{abstract}
Background: Emergency Department (ED) crowding is an ongoing problem in Canada. Several performance metrics have been established to help benchmark different EDs to improve care. A nurse program was implemented across Ontario to reduce paramedic time to offload ED patients. Our objective was to assess the impact of utilizing an ambulance offload nurse (AON) on ED length of stay.

Methods: A before-after cohort study was conducted at one large hospital in Canada. A comparison was made pre-and post-implementation of an AON from January to March. The differences in median times for ED length of stay (EDLOS), physician initial assessment (PIA) time and time to disposition (TTD) were analyzed for all patients who presented to the ED via ambulance.
\end{abstract}

Results: There were 2,198 ambulance arrivals in 2009, and 2,785 for 2013. Following the addition of an AON, we found a statistically significant decrease in median PIA time ( 0.13 hours, $p=0.02)$, but a statistically significant increase in median EDLOS $(0.27$ hours, $p=0.048)$ and TTD $(1.25$ hours, $p<0.001)$. Further subgroup analysis concluded that PIA time, post-implementation, was most improved in patients $<65$ years old ( 0.92 hours, $\mathrm{p}=0.228$ ) and that EDLOS and TTD decreased significantly in CTAS 4 patients (3.58 hours, $p<0.001$ and 3.69 hours, $p=0.001$ respectively).

Conclusions: The presence of an AON demonstrated improvements in certain ED metrics but no improvement in others. While these improvements provide some evidence in the utility of AON, further studies are needed to further understand the impact of ED metrics.

Keywords: Ambulance offload; Ed Crowding; Triage Nurse.

\section{Summary}

\section{What is already known about the topic?}

- Ambulance offload nurses are useful in getting ambulances offloaded quicker, allowing ambulances to return to the streets sooner to attend to other calls.

- What isn't clear is how the use of an ambulance offload nurse impacts other time metrics in the emergency department, such as emergency department length of stay and physician initial assessment time. 


\section{What this paper adds?}

- Our study suggests that the presence of an ambulance offload nurse benefited the physician initial assessment time in the emergency department.

- We believe that ongoing implementation of an ambulance offload nurse should continue as their benefit is beyond just the ambulances.

\section{Introduction}

Emergency Department (ED) crowding is an ongoing, increasingly intractable issue, and is likely to worsen with an aging population and concomitant medical complexity. Annually, $13 \%$ of Canadians access the ED for health care, resulting in more than 11 million visits across Canadian EDs [1]. Many causes of ED crowding have been posited and studied, some of which include shortage of hospital beds for admitted patients, lack of access to primary care specialists, and increasing medical complexity of the patient population $[2,3]$. ED crowding is also known to negatively impact patient care through various factors including but not limited to longer wait-times for treatment for time-sensitive conditions, increased chances of medical error, and patients wanting to leave against medical advice $[4,5]$.

The use of ambulance offload nurses (AON) in the ambulance offload area was an initiative by the Ontario, Canada's ministry of health [6] to help reduce the burden of time spent by paramedics in the ED waiting for transfer of care. According to this report, approximately 12 million dollars are spent funding the AON initiative annually. Recent literature has shown that AON's ease the congestion in EDs [7]. An AON in the triage area may help to quickly offload ambulance patients, decrease ambulance offload time (AOT) and allow ambulance crews to leave the ED sooner [8]. The impact of AONs on the rest of the care pathway (i.e. from the ambulance crew handing over the patient to the ED care until disposition of the patient) has never been studied in a Canadian context. The objective of this study was to look at the utility of the AON on the various ED metrics (ED Length of Stay (EDLOS), Physician Initial Assessment (PIA) time and Time to disposition (TTD)). While there is a great deal of rational for the use of an AON for getting the ambulance crew back on the street and improving offload times, the challenge is whether or not they improve other system processes. This study sought to establish the trend of performance on several metrics in pre and post AON settings. We have also contextualized differences with changes in acuity and volume to estimate the effect of the AON on patient flow. This is the first study to look at the utility of an AON based on predefined performance metrics in a Canadian context.

\section{Methods}

\section{Study design}

This was a single-center retrospective study using preand post- implementation of the AON. Institutional research ethics was obtained through the research ethics board at Hamilton Health Sciences. Patients who presented via ambulance at Hamilton General Hospital (HGH) in 2009 and 2013 were included. The year 2009 was the most current data available to utilize as a comparison group that did not have the intervention (i.e. the last year when an AON was not used), it was after this point that an AON was implemented across Ontario. A four-year gap was then chosen deliberately to help alleviate some of the concerns regarding the initial learning phase that occurs with the implementation of a new strategy (i.e. AON usage). Furthermore, other systemic changes in the hospital occurred over the years that could confound the results of the study.

\section{Study setting}

$\mathrm{HGH}$ is a 304 bed, academic, tertiary care, urban hospital. $\mathrm{HGH}$ has an ED census of approximately 40,000 ED visits annually, with approximately 12,000 of them arriving by ambulance. $\mathrm{HGH}$ receives approximately $28 \%$ of its daily patient visits by ambulance.

\section{Population}

For each year of study, three months (January to March) were selected to avoid seasonal variation. We included all patients who arrived by ambulance and were categorized by CTAS score of 2 to 5. Patients who were categorized as CTAS 1 were excluded as these patients have an immediate offload time and PIA time of zero, given their acuity. Patients who arrived by other means such as air ambulance were also excluded. Data were obtained from Hamilton Health Sciences internal database, which collects and stores various metrics and markers for use with its own operations and quality improvement.

\section{Outcome measures}

The primary outcome was to compare the median EDLOS in hours, before and after the implementation of an AON. The secondary outcome measures were to compare the median PIA time and TTD in hours before and after the implementation of an AON. Data points were collected using time stamps on paper records of treatment that are transcribed electronically.

\section{Data analysis}

Demographic data for each cohort were compared to determine similarity using a standard t-test. A chi square test was used to compare categorical variables (age, gender and CTAS category). For our primary outcome, EDLOS, the time was defined from the time of arrival to the time of discharge/ admission to hospital ward. Similarly, for our secondary outcomes, the PIA, and TTD times were calculated using the time of arrival as the initial time. Data for each measure were tested for normality using the Kolmogorov-Smirnov test.

For comparing the differences in EDLOS, PIA time and TTD, they were analyzed using non-parametric statistics given the non-normality of their distribution. To test for significance between the two groups, we used an independent-samples median test. $A p<0.05$ was determined a-priori to be significant.

A subgroup analysis for age and CTAS scores was used to determine if there were any significant differences. The data were again tested for normality using the Kolmogorov- 
Smirnov test which revealed a non-normal distribution for all three measures. The selected cut-offs fell into three groups; group 1) < 19 years of age group; 2) 19-65 years of age group and 3) $>65$ years of age. The same statistical process was followed for each CTAS level ranging from CTAS 2 to CTAS 5 .

A regression analysis was conducted to adjust for the covariates of age, gender and CTAS score for each of the outcomes.

Data were analyzed using Statistical Package for the Social Sciences (IBM ${ }^{\circledR}$ Sassing.; Statistics version 23; Chicago, IL).

\section{Results}

For the selected study period January-March, there were 2,362 ambulances in 2009 and 3,159 in 2013. There were a total of 519 CTAS 1 patients that were excluded.

The differences between the two groups are summarized in table 1. In 2009, the mean age was 59.8 years of age (range 12-102), while in 2013, it was 61.6 years of age (range 15-103), $(p<0.05)$. The majority of ED patients $(54.8 \%$ in 2009 and $52.7 \%$ for 2013) were between the age of 19 and 65 years old with a small proportion being less than 19 years of age (1.5\% in 2009 and $1.1 \%$ in 2013).

Table 1. Group Characteristics for 2009 and 2013.

\begin{tabular}{|l|c|c|c|}
\hline Groups & $\begin{array}{c}2009 \\
\mathrm{~N}=2198\end{array}$ & $\begin{array}{c}2013 \\
\mathrm{~N}=2785\end{array}$ & $\mathrm{P}$-Value \\
\hline \multicolumn{4}{|l|}{ Demographics } \\
\hline $\begin{array}{l}\text { Age (mean years) } \\
\text { (Range) }\end{array}$ & $\begin{array}{c}59.8 \\
(12-102)\end{array}$ & $\begin{array}{c}61.6 \\
(15-103)\end{array}$ & $\mathrm{P}<0.05$ \\
\hline Age $<19$ years (\%) & $34(1.5 \%)$ & $31(1.1 \%)$ & $\mathrm{P}<0.33$ \\
\hline Age 19-65 years (\%) & $1205(54.8 \%)$ & $1469(52.7 \%)$ & $\mathrm{P}<0.12$ \\
\hline Age $>65$ years (\%) & $959(43.6 \%)$ & $1285(46.1 \%)$ & $\mathrm{P}<0.05$ \\
\hline Male & $1163(52.9 \%)$ & $1457(52.3 \%)$ & $\mathrm{P}<0.69$ \\
\hline Canadian Triage and Severity Score (CTAS) \\
\hline 2 & $695(31.6 \%)$ & $1017(36.5 \%)$ & $\mathrm{P}<0.05$ \\
\hline 3 & $1137(51.7 \%)$ & $1654(59.4 \%)$ & $\mathrm{P}<0.05$ \\
\hline 4 & $338(15.4 \%)$ & $108(3.9 \%)$ & $\mathrm{P}<0.05$ \\
\hline 5 & $28(1.3 \%)$ & $6(0.2 \%)$ & $\mathrm{P}<0.05$ \\
\hline
\end{tabular}

Table 3. Subgroup Analysis by Age and CTAS Categories for 2009 and 2013.

\begin{tabular}{|c|c|c|c|c|c|c|c|c|c|c|}
\hline \multirow[b]{2}{*}{ AGE } & & \multicolumn{3}{|c|}{$2009(\mathrm{~N}=2198)$} & \multicolumn{3}{|c|}{$2013(\mathrm{~N}=2785)$} & \multicolumn{3}{|l|}{ P- Value } \\
\hline & & EDLOS & PIA & TTD & EDLOS & PIA & TTD & EDLOS & PIA & TTD \\
\hline $\begin{array}{l}\text { Group } \\
(\text { Age }<19)\end{array}$ & \begin{tabular}{|l|l}
1 & $\mathrm{~N}$ \\
Median (h) \\
IQR
\end{tabular} & \begin{tabular}{|l|}
4 \\
4.47 \\
$(3.08-7.49)$
\end{tabular} & \begin{tabular}{|l}
13 \\
0.30 \\
$(0.18-0.47)$
\end{tabular} & $\begin{array}{l}34 \\
3.35 \\
(2.78-5.85)\end{array}$ & \begin{tabular}{|l|}
31 \\
3.78 \\
$(2.00-5.88)$
\end{tabular} & $\begin{array}{l}31 \\
0.77 \\
(0.25-1.53)\end{array}$ & $\begin{array}{l}31 \\
3.02 \\
(1.78-4.77)\end{array}$ & 0.705 & 0.031 & 0.887 \\
\hline $\begin{array}{l}\text { Group } \\
\text { (Age 19-65) }\end{array}$ & $\begin{array}{l}2 \\
\text { Median (h) } \\
\text { IQR }\end{array}$ & \begin{tabular}{|l|}
1205 \\
4.90 \\
$(2.87-8.02)$
\end{tabular} & \begin{tabular}{|l}
694 \\
0.68 \\
$(0.33-1.52)$ \\
\end{tabular} & \begin{tabular}{|l|}
1205 \\
4.58 \\
$(2.60-6.80)$
\end{tabular} & $\begin{array}{l}1469 \\
4.83 \\
(2.95-8.35)\end{array}$ & $\begin{array}{l}1316 \\
0.68 \\
(0.33-1.52) \\
\end{array}$ & \begin{tabular}{|l|}
1469 \\
4.65 \\
$(2.93-7.43)$ \\
\end{tabular} & 0.698 & 0.000 & 0.557 \\
\hline $\begin{array}{l}\text { Group } \\
(\text { Age }>65)\end{array}$ & \begin{tabular}{|l|l}
$\mathrm{N}$ \\
Median (h) \\
IQR
\end{tabular} & $\begin{array}{l}959 \\
7.15 \\
(3.95-13.0) \\
\end{array}$ & $\begin{array}{l}599 \\
1.02 \\
(0.50-2.00)\end{array}$ & $\begin{array}{l}959 \\
6.33 \\
(4.10-8.73)\end{array}$ & $\begin{array}{l}1285 \\
7.73 \\
(4.64-14.0)\end{array}$ & $\begin{array}{l}1214 \\
0.92 \\
(0.38-1.79)\end{array}$ & \begin{tabular}{|l|}
1285 \\
7.10 \\
$(4.95-9.48)$
\end{tabular} & 0.050 & 0.228 & 0.000 \\
\hline CTAS categc & jory & EDLOS & PIA & TTD & EDLOS & PIA & TTD & EDLOS & PIA & TTD \\
\hline 2 & $\begin{array}{l}\text { N } \\
\text { Median (h) } \\
\text { IQR }\end{array}$ & $\begin{array}{l}695 \\
6.03 \\
(3.32-10.6) \\
\end{array}$ & $\begin{array}{l}390 \\
0.53 \\
(0.23-0.90) \\
\end{array}$ & \begin{tabular}{|l|}
695 \\
4.87 \\
$(2.82-7.17)$
\end{tabular} & \begin{tabular}{|l|}
1017 \\
6.95 \\
$(3.78-11.6)$ \\
\end{tabular} & \begin{tabular}{|l|}
1017 \\
0.48 \\
$(0.28-0.85)$
\end{tabular} & \begin{tabular}{|l|}
1017 \\
5.88 \\
$(3.63-8.10)$
\end{tabular} & 0.030 & 0.341 & 0.000 \\
\hline 3 & $\begin{array}{l}\text { N } \\
\text { Median (h) } \\
\text { IQR }\end{array}$ & $\begin{array}{l}1134 \\
6.02 \\
(3.43-10.1)\end{array}$ & $\begin{array}{l}700 \\
1.12 \\
(0.58-2.17)\end{array}$ & \begin{tabular}{|l|}
1134 \\
5.80 \\
$(3.51-8.58)$
\end{tabular} & \begin{tabular}{|l|}
1654 \\
5.86 \\
$(3.50-10.1)$
\end{tabular} & $\begin{array}{l}1654 \\
1.14 \\
(0.50-2.10)\end{array}$ & \begin{tabular}{|l}
1654 \\
5.92 \\
$(3.68-8.80)$
\end{tabular} & 0.459 & 0.804 & 0.548 \\
\hline 4 & $\begin{array}{l}\mathrm{N} \\
\text { Median (h) } \\
\text { IQR }\end{array}$ & \begin{tabular}{|l|}
338 \\
4.79 \\
$(2.80-7.38)$
\end{tabular} & $\begin{array}{l}204 \\
1.41 \\
(0.82-2.62) \\
\end{array}$ & $\begin{array}{l}338 \\
4.82 \\
(2.80-6.92)\end{array}$ & $\begin{array}{l}108 \\
3.58 \\
(2.50-5.58) \\
\end{array}$ & $\begin{array}{l}108 \\
1.30 \\
(0.43-2.48)\end{array}$ & $\begin{array}{l}108 \\
3.69 \\
(2.57-6.13)\end{array}$ & 0.000 & 0.737 & 0.001 \\
\hline 5 & $\begin{array}{l}\mathrm{N} \\
\text { Median (h) } \\
\text { IQR }\end{array}$ & $\begin{array}{l}28 \\
3.45 \\
(2.22-5.00)\end{array}$ & $\begin{array}{l}11 \\
1.30 \\
(1.33-2.60)\end{array}$ & $\begin{array}{l}28 \\
3.46 \\
(2.22-5.00)\end{array}$ & $\begin{array}{l}6 \\
5.57 \\
(0.64-10.0)\end{array}$ & $\begin{array}{l}6 \\
1.16 \\
(0.00-3.20)\end{array}$ & $\begin{array}{l}6 \\
5.57 \\
(0.64-10.0)\end{array}$ & 0.653 & 1.00 & 0.653 \\
\hline
\end{tabular}

EDLOS: Emergency Department length of stay; PIA: Physician Initial Assessment; TTD: Time to Disposition; CTAS: Canadian Triage and Acuity score. 


\section{Regression analysis}

When adjusting the covariates of age, gender and CTAS using a linear regression, we found that age and CTAS were both statistically significant $(p<0.05)$ for each outcome. See table 4 .

Table 4. Linear regression adjusting for age, gender and CTAS for each outv come.

\begin{tabular}{|l|l|}
\hline EDLOS & $\mathrm{P}<0.001$ \\
\hline Age & $\mathrm{P}=0.068$ \\
\hline Gender & $\mathrm{P}<0.001$ \\
\hline CTAS & $\mathrm{P}<0.050$ \\
\hline PIA time & $\mathrm{P}=0.082$ \\
\hline Age & $\mathrm{P}<0.001$ \\
\hline Gender & $\mathrm{P}<0.001$ \\
\hline CTAS & $\mathrm{P}=0.494$ \\
\hline TTD & $\mathrm{P}<0.001$ \\
\hline Age & \\
\hline Gender & \\
\hline CTAS &
\end{tabular}

EDLOS: Emergency Department length of stay; PIA: Physician Initial Assessment; TTD: Time to Disposition; CTAS: Canadian Triage and Severity score

\section{Discussion}

Our study shows that the AONs had some significant findings on all of the performance metrics examined. Some of the performance metrics were shown to worsen from 2009 to 2013 (i.e. the EDLOS increased). It is possible that a benefit may have existed in mitigating an even higher EDLOS, PIA time and TTD, particularly in the context of higher CTAS and higher numbers of the later year patients, but that is a conjecture rather than a conclusion based on evidence. Moreover, other data would need to be examined to fully understand these findings, such as other hospital issues like over-crowding and staffing changes that may have coincided during this studies timeframe.

We found that there was an increase in median EDLOS of 0.27 hours over the two cohorts, multiple reasons exist that may explain this. Firstly, 2013 had an older population, with $2.5 \%$ more patients $>65$ years. Studies suggest that an older population is known to increase EDLOS [9]. Secondly, the patients in 2013 had higher CTAS scores (i.e. were sicker) - in the 2013 there were $4.9 \%$ more CTAS 2's than in 2009 and $7.7 \%$ more CTAS 3's. This is in addition to the higher number of patients in the CTAS 2 and 3 categories in 2013 as compared to those in 2009 could explain our findings. According to available evidence, assuming that CTAS is an indicator of acuity and of how sick a patient is, then we know that these patients are known to require more time and resources leading to a longer EDLOS $[10,11]$.

One group of Australian researchers conducted a similar study that looked at patient outcomes with the presence of an AON and without [7]. The authors discovered that certain patient groups benefited from the presence of an $A O N$, however the result was not sustained. The authors of this study also identified that various metrics including PIA time improved with the presence of an AON, while EDLOS did not. These findings are in line with our study findings.
There are several limitations to our study. First, this was a retrospective data review which is susceptible to bias in the data collection and bias by design. We suggest future studies to be designed in a prospective manner comparing two similar sites in the same geographic area and timeframe, with one having an AON and one without. Second, the time difference between the two cohorts was 4 years. However, this was deliberately done as the funding for the AON was not consistent in the earlier years of adoption and a comparison group was needed where the AON was not in the learning curve phase. Furthermore, choosing to use more current data would have been prone to other confounders as many other hospital-wide interventions to improve efficiencies may have occurred during those years. Third, the metrics that were utilized were predefined and aligned with the provincial markers. While these metrics have some utility in defining the role of the AON nurse, a metric system based on overall healthcare resources and patient driven outcomes would be far superior in our opinion. Finally, there were some missing data, specifically for the PIA times for 2009. This was simply due to the quality of data that was received. Moreover, it should be mentioned that there were also several potential confounders that were not adjusted for in this study including: overall ED volumes, hospital bed occupancy rates, ED wait times and consultant availability. All of these could further explain our results. This study was a univariate analysis that looked at one predictor (i.e. presence of an AON). However, to help remedy this, we conducted a subgroup analysis and a regression analysis to look for patterns in different age-cut-offs, gender and CTAS scores to determine where the largest impact would be.

Our study showed that the presence of an AON benefited the PIA time in the ED, primarily for patients $<65$ years of age and in CTAS level 4 patients. Furthermore, after adjusting for the covariates of age and CTAS, we found that an AON significantly affects the EDLOS and TTD. As mentioned earlier, the AON program is funded to enable the ambulance crew to return to the street sooner and currently has an expenditure of approximately 12 million dollars annually. It is unclear at a macroeconomic level what the opportunity costs of the AON is, and whether these resources can be used to improve the overall outcomes based on value added care at a patient level. Such programs have a way of becoming entrenched and difficult to scale back once implemented, making it more challenging to study the utility and costs of this initiative.

This study was the first of its kind done in a Canadian setting. The study revealed that the three different performance measures: EDLOS, PIA time and TTD all had statistically significant findings. Based on our findings, an AON is beneficial to EDLOS, TTD and PIA time in EDs. Their impact was seen predominately in patients $<65$ years of age and in CTAS level 4 patients. Their implementation has a positive effect on the movement of patients in urban, tertiary care ED and although the findings were modest, we recommend that their use should be continued as standard of practice until further, prospective studies are conducted to state otherwise. 


\section{References}

1. Canadian Institute for Health Information. NACRS Emergency Department Visits and Length of Stay. 2016-2017. National Ambulatory Care Reporting System. ClHI. 2017.

2. Friesen MR, Strome T, Mukhi S, McLoed R. Load Balancing at Emergency Department usin 'Crowd informing'. Online J Public Health Inform. 2011; 3(2). doi: 10.5210/ojphi.v3i2.3520

3. Lee YJ, Shin SD, Lee EJ, Cho JS, Cha WC. Emergency Department Overcrowding and Ambulance Turnaround Time. PLoS One. 2015; 10(6): e0130758. doi: 10.1371/journal.pone.0130758

4. Hoot N, Aronsky D. Systematic Review of Emergency Department Crowding: Causes, Effects and Solutions. Ann Emerg Med. 2008; 52(2): 126-136. doi: 10.1016/j.annemergmed.2008.03.014

5. Wang H, Robinson RD, Garrett JS, et al. Use of the SONET Score to Evaluate High Volume Emergency Department Overcrowding: A Prospective Derivation and Validation Study. Emerg Med Int. 2015; 2015: 401757. doi: 10.1155/2015/401757
6. Office of the Auditor General of Ontario. Land Ambulance Services. Ministry of Health and Long-Term Care; 2013.

7. Greaves $T$, Mitchell M, Zhang P, Crilly J. The impact of an Emergency Department ambulance offload nurse: A retrospective comparative study. Int Emerg Nurs. 2017; 32: 39-44. doi: 10.1016/j.ienj.2016.12.005

8. Clarey A, Allen M, Brace-McDonnell S, Cooke MW. Ambulance handovers: can a dedicated ED nurse solve the delay in ambulance turnaround times? Emerg Med J. 2014; 31(5): 419-420. doi: 10.1136/emermed-2012-202258

9. Crilly J, Chaboyer W, Wallis M, Thalib L, Green D. Predictive outcomes for older people who present to the Emergency Department. Australas Emerg Nurs J. 2008; 11(4): 178-183. doi: 10.1016/j.aenj.2008.07.002

10. Moe J, Kirkland S, Ospina MB, et al. Mortality, admission rates and outpatient use among frequent users of emergency departments: a systematic review. Emerg Med J. 2016; 33(3): 230-236. doi: 10.1136/ emermed-2014-204496

11. Rask KJ, Williams MV, McNagny SE, Parker RM, Baker DW. Ambulatory Health Care Use by Patients in a Public Hospital Emergency Department JGenInternMed.1998;13(9):614-620.doi:10.1046/j.1525-1497.1998.00184.x 